\title{
A Coastal Flood Event Database for the Southeastern Georgia and Southeastern South Carolina Coast and the Operational Implementation of a Tide Forecast Tool
}

\author{
BLAIR S. HOLLOWAY \\ NOAA/National Weather Service, Charleston, South Carolina \\ (Manuscript received 4 April 2021; review completed 16 October 2021)
}

\begin{abstract}
Coastal flooding occurs when saltwater inundates normally dry land and the resulting impacts can range from minor flooding of low-lying areas along the coast, to significant damage to property and structures. Previous research consistently suggests that if sea-level rise continues to increase along the East Coast of the United States, coastal flooding will occur more frequently. In order to document the history of coastal flooding along the southeastern Georgia and southeastern South Carolina coast, a coastal flood event database was created for National Ocean Service tide gauges located in Charleston Harbor, South Carolina and Fort Pulaski, Georgia. Trends from the data show that coastal flooding is occurring more frequently with time at both tide gauges, particularly over the last five to ten years. Because of the increased frequency and worsening impacts of tidal flooding, a tide forecast tool is implemented operationally in an effort to improve deterministic tide forecasts. This study extends the dataset used in the Charleston Harbor forecast tool, expands the tool to Fort Pulaski, and compares the synoptic category forecast equations to an all-inclusive equation that does not differentiate by synoptic category. Results show that there is virtually no difference in the forecast accuracy between the all-inclusive forecast equation and the specific forecast equations based on synoptic category. Furthermore, the all-inclusive forecast equation can be implemented operationally, will help improve deterministic tide forecasts, and will likely aid in the decision-making process for Coastal Flood Watches, Warnings, and Advisories issued by the National Weather Service office in Charleston, South Carolina.
\end{abstract}

\section{Introduction}

Tides are the regular rise and fall of the ocean surface, resulting from the gravitational forces exerted by the sun and the moon (Thurman and Trujillo 2004). Tide heights vary throughout the year, primarily driven by the position of the moon in its orbit around the earth and the proximity of the earth to the sun. In general, higher tides occur when the moon is at or near new or full phase and when it is closest to the earth on its elliptical orbit (perigee) (NOAA 2019). Tides are also modulated by geographic location of the coastal domain, including configuration of the coastline and local bathymetry. The East Coast of the continental United States experiences a semidiurnal tide cycle, which means two high tides and two low tides of approximately equal amplitude occur each day. In addition to astronomical and geographic influences, tides can be significantly altered by meteorological parameters, including ambient air pressure and wind speed and direction. Under certain circumstances, weather conditions can aid in pushing tide heights well above the astronomical expected level. When tide levels become sufficiently high, coastal flooding can occur as saltwater inundates normally dry land. Coastal flooding can range from minor impacts such as flooding of lowlying areas near the waterfront, to significant impacts including damage to homes and businesses, a prolonged disruption of travel, and even the isolation of coastal communities. Because of the cyclical nature of tides, coastal flooding is repetitive and routinely inundates the same areas. This repetitive flooding can cause longterm damage to property and critical infrastructure such as roads, causing state and local governments to

Corresponding author address: Blair S. Holloway, 5777 S Aviation Avenue, North Charleston, SC 29406. 
implement costly projects to build new infrastructure or adapt and maintain existing infrastructure (Campbell Jones et al. 2019). Also, studies show that in response to expected sea level rise, coastal flooding could generate property value exposure that is comparable to, or larger than, historical extreme events (Moftakhari et al. 2017). Furthermore, many coastal communities are developing detailed strategies to mitigate the impacts of flooding and planning resilience projects to adapt to sea-level rise in the future (Charleston 2019). Such strategic planning is important because in cities such as Charleston, South Carolina, not only is the annual number and duration of flood events expected to increase with time, but so is the total land area impacted (Morris and Renken 2020).

The National Weather Service (NWS) accomplishes its mission of protecting life and property, in part, through the issuance of watches and warnings for hazardous weather. For coastal flooding, this includes issuing Coastal Flood Watches, Warnings, and Advisories when observed tide levels are expected to rise above pre-determined height thresholds that correspond to Minor, Moderate, and Major salt water flooding. The area of forecast and warning responsibility for the NWS office in Charleston, South Carolina (NWS Charleston) includes the coastline of southeastern Georgia and southeastern South Carolina. Within this area, there are two National Ocean Service (NOS) tide gauges with long historical records of observations. One gauge is located in Charleston Harbor near Charleston, South Carolina (NOS site 8665530) and has continuously recorded tide measurements since 1921. The other gauge is located near the mouth of the Savannah River at Fort Pulaski, Georgia (NOS site 8670870) and has continuously recorded tide measurements since 1935. Both sites clearly show an increasing trend in sea level, measuring the equivalent of a nearly $0.34 \mathrm{~m}(1.1 \mathrm{ft})$ rise in 100 years (Fig. 1), and both display large increases in the frequency of coastal flood events due to this rise in sea level (Sweet et al. 2014). Furthermore, all NOS sea-level rise scenarios (Sweet et al. 2017) depict a continued increase in coastal flood frequency along most of the United States coastline (Sweet et al. 2018). Other studies, including Moftakhari et al. (2015), also have shown that coastal flood frequency will rapidly increase in the future.

Because coastal flooding is identified as an issue of importance for coastal regions, creating and maintaining a detailed database of coastal flood events would provide quantitative context to the occurrence of events and trends over time. The NOS has completed extensive

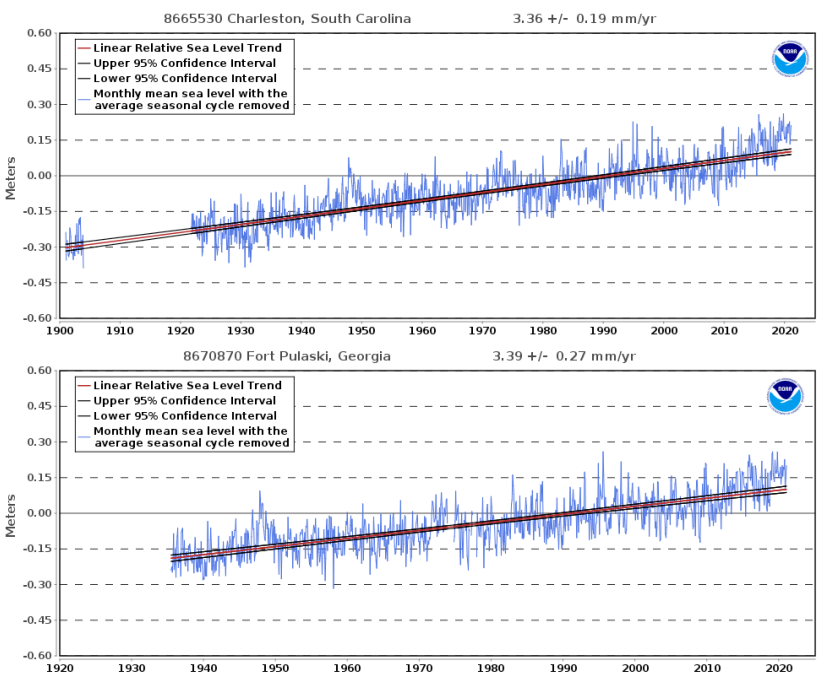

Figure 1. Monthly mean sea level at Charleston Harbor, SC (top) and Fort Pulaski, GA (bottom). Plots taken from NOS CO-OPS for Charleston Harbor, SC (link) and Fort Pulaski, GA (link). Click image for an external version; this applies to all figures hereafter.

work documenting the frequency of coastal flood events across the United States (Sweet et al. 2014), but this work has focused on the number of flood days as opposed to the total number of flood events (individual tide events). The first purpose of this study is to create a coastal flood event database for the NWS Charleston forecast area, documenting all observed peak tides that reached or exceeded the threshold for coastal flooding at the Charleston Harbor and Fort Pulaski gauges.

Although documenting the history of coastal flooding at these sites is important, applying this database to improve tide level forecast accuracy is vital to the coastal flood program at NWS Charleston and the partners it serves. Starting in late 2016, NWS Charleston began routinely forecasting tides at Charleston Harbor and Fort Pulaski as part of the Total Water Level (TWL) initiative in the NWS's Eastern Region. TWL forecasts are created using forecaster input monitoring recent tide trends, water level model guidance, and synoptic and mesoscale pattern recognition to adjust astronomical tide predictions and produce deterministic tide level forecasts. TWL forecasts are displayed publicly on Advanced Hydrologic Prediction Service (AHPS) hydrographs and show the forecasted tide levels relative to NWS flood categories (Fig. 2). Examples of water level model guidance utilized includes both the deterministic and probabilistic Extra-Tropical Storm Surge (ETSS) model and the Extratropical Surge and Tide Operational Forecast System (ESTOFS). 


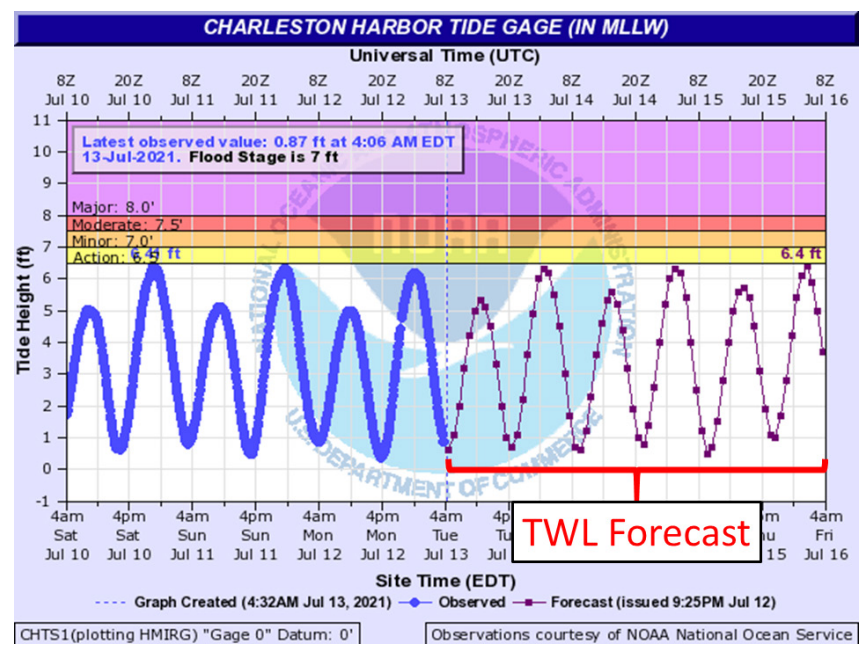

Figure 2. AHPS hydrograph for the Charleston Harbor, SC tide gauge, highlighting the TWL forecast produced by NWS Charleston.

The second purpose of this study is to develop a tide forecast tool, following $\mathrm{Coz}$ et al. (2021), which can help improve the TWL forecast and increase forecaster confidence when making decisions regarding Coastal Flood Watches, Warnings, and Advisories. Unlike existing tide model guidance that is mostly generated on a six-hourly production cycle, this forecast tool could be used on an as-needed basis to create TWL forecast guidance. The resulting improvement in tide forecast accuracy can help coastal communities more effectively prepare for coastal flooding. The following sections detail the methods for creating the coastal flood event database, the development and testing of the forecast tool, and a discussion of the operational implementation of the forecast tool.

\section{Coastal flood event database}

\section{a. Data collection}

All tide data for the coastal flood event database were retrieved using the NOS Center for Operational Oceanographic Products and Services (CO-OPS) Tides and Currents web page (Link). Coastal flood events were identified when an observed peak tide reached or exceeded the NWS Charleston minor flood category threshold of $2.13 \mathrm{~m}$ (7.0 ft) Mean Lower Low Water (MLLW) at Charleston Harbor (NOS site 8665530) and $2.896 \mathrm{~m}(9.5 \mathrm{ft})$ MLLW at Fort Pulaski (NOS site 8670870). The NOS CO-OPS period of record for each site differed, so the event database includes all observed peak tides that reached or exceeded these thresholds from 1 January 1922 to 31 December 2020 at Charleston Harbor and 1 January 1936 to 31 December 2020 at Fort Pulaski. Each observed peak tide that reached or exceeded these thresholds constituted an event, and there were numerous times during the period of record when two events occurred on the same calendar day.

Operationally, NWS Charleston uses the sixminute water level in real time to monitor tide heights, to identify the peak tide level for Local Storm Reports (LSRs), and to catalog historic crests for display on AHPS web pages (Link). For the coastal flood event database, NOS CO-OPS-verified Hourly Height water level was used from 1 January 1922 through 30 November 1979, verified High/Low (H/L) water level was used from 1 December 1979 through 30 November 1995, and verified six-minute water level was used from 1 December 1995 through 31 December 2020. After all available coastal flood events were identified for both sites, events were organized by month and year for analysis. The full database for both Charleston Harbor, South Carolina and Fort Pulaski, Georgia is available on the web (Link) and will be updated and maintained as coastal flood events occur in the future.

\section{b. Charleston Harbor, South Carolina data analysis}

In total, 1,124 coastal flood events occurred from 1922 to 2020 as measured at the Charleston Harbor NOS tide gauge. There is clearly an increasing trend of occurrence across the 99-year time period, culminating in 89 events in 2019 and 68 events in 2020, the two highest years on record (Fig. 3). The increasing trend becomes even more pronounced when considering the average number of events per year in each decade. From the 1920's to the 2010's, the average number of events per year has increased dramatically from 0.8 to 42.4 (Table 1). Furthermore, the last five years of the time period (2016 to 2020) account for $27 \%$ (300 of $1,124)$ of all events in the database and all but one of those years rank in the top five among all years. The increasing trend is also obvious at the $2.286 \mathrm{~m}(7.5 \mathrm{ft})$ MLLW (Moderate coastal flooding) and $2.438 \mathrm{~m}(8.0$ ft) MLLW (Major coastal flooding) thresholds (Fig. 4). In fact, $\sim 48 \%$ of all events at or above $2.286 \mathrm{~m}(7.5$ ft) MLLW (97 of 203), and 61\% of all events at or above $2.438 \mathrm{~m}(8.0 \mathrm{ft}$ ) MLLW or higher (22 of 36) have occurred since 2015. Seasonally, there are some minor fluctuations from January through August, but the most striking signal is that nearly half of all events (548 of $1,124)$ occur in the September through November time 


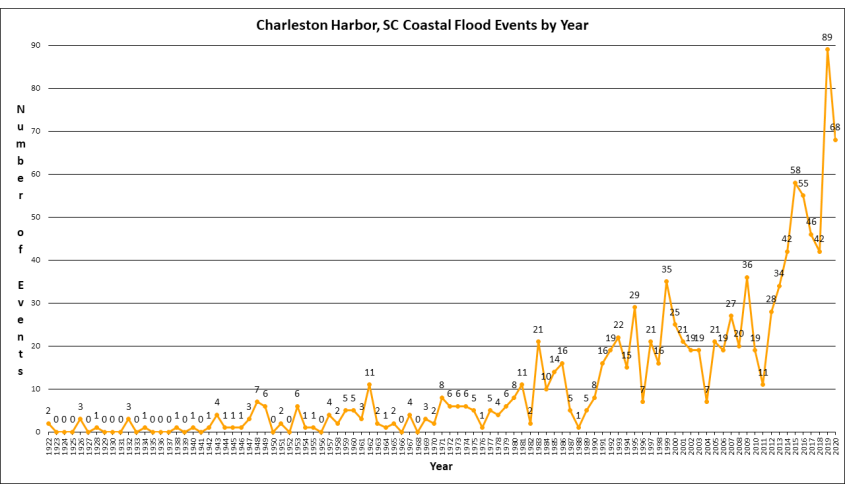

Figure 3. Total coastal flood events (1922-2020) by year for Charleston Harbor, SC.

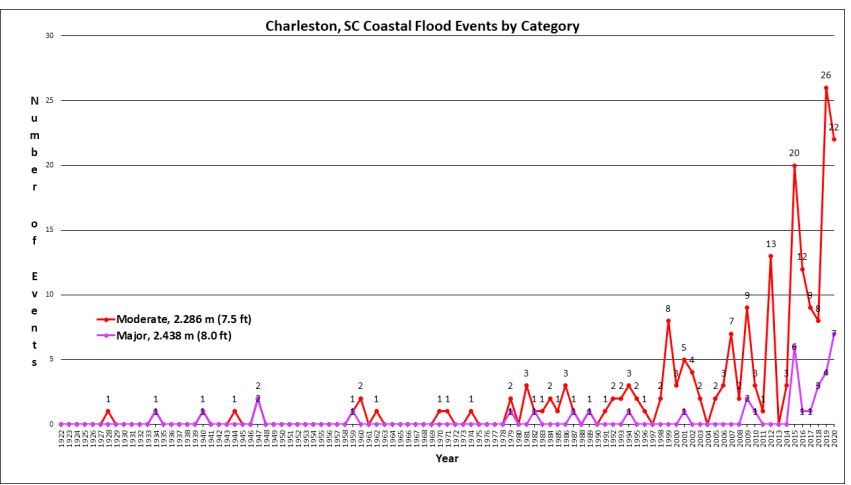

Figure 4. Total coastal flood events (1922-2020) by year that reached or exceeded Moderate and Major flood category at Charleston Harbor, SC.

period (Fig. 5). Overall, these trends are consistent with the data presented by Sweet et al. (2014).

\section{c. Fort Pulaski, Georgia data analysis}

At the Fort Pulaski, Georgia NOS tide gauge, 126 coastal flood events occurred during the 1936 to 2020 time period. Like Charleston Harbor, there is clearly an increasing trend of occurrence across the 85-year time period (Fig. 6). The highest number of events for any single year was 15 , which occurred in 2015,2019 , and 2020. The increasing trend is notable when looking at the average number of events per year in each decade, though not as striking as at Charleston Harbor. From the 1930 's to the 2010's, the average number of events per year increased from 0 to 6.5 (Table 1). More than $40 \%$ of all events (53 of 126) occurred in the last five years of the time period (2016 to 2020) and three of those years rank in the top five among all years. An increasing trend is also noted at the $3.048 \mathrm{~m}(10.0 \mathrm{ft})$ MLLW (Moderate coastal flooding) level, though this trend is only apparent

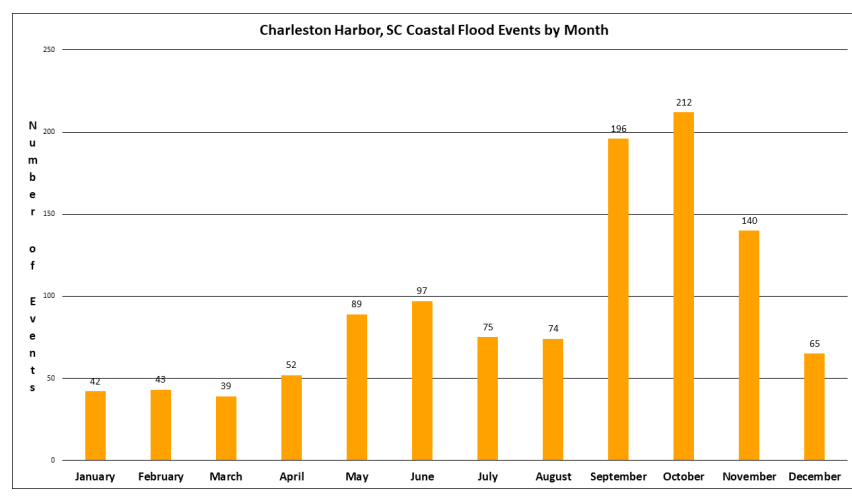

Figure 5. Coastal flood events by month (1922-2020) for Charleston Harbor, SC.

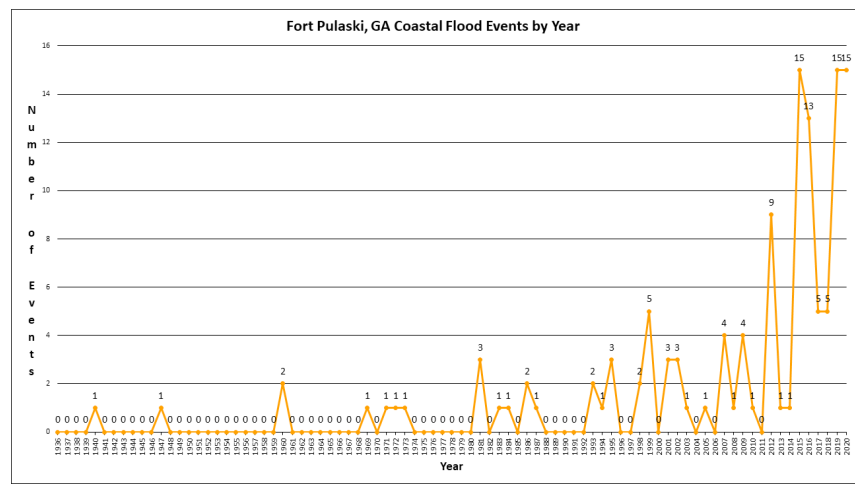

Figure 6. Same as in Figure 3, but for Fort Pulaski, GA (1936-2020).

in the last five years (Fig. 7). Furthermore, the $3.20 \mathrm{~m}$ (10.5 ft) MLLW (Major coastal flooding) level has been only breached three times, all of which were due to tropical cyclones [unnamed hurricane (1947), Matthew (2016), and Irma (2017)]. More than $60 \%$ of all events (11 of 18) with a peak tide of $3.048 \mathrm{~m}$ (10.0 ft) MLLW or higher have occurred since 2015. Seasonally, trends were similar to Charleston Harbor as $\sim 48 \%$ of all events (60 of 126) occurred in the September-November time period (Fig. 8).

\section{Tide forecast tool}

\section{a. Data and methods}

NWS Charleston produces a deterministic TWL forecast expressed in tenths of a foot for the Charleston Harbor and Fort Pulaski tide gauges at least twice a day due to the semidiurnal tide cycle, and uses this forecast to make decisions regarding the issuance of Coastal Flood Watches, Warnings, and Advisories. Seeking to improve TWL forecasts, a tide forecast tool was 
Table 1. Average number of coastal flood events per year in each decade for Charleston Harbor, SC and Fort Pulaski, GA.

\begin{tabular}{|c|c|c|}
\hline Decade & $\begin{array}{c}\text { Charleston Harbor, SC (Average } \\
\text { Events per Year) }\end{array}$ & $\begin{array}{c}\text { Fort Pulaski, GA } \\
\text { (Average Events per Year) }\end{array}$ \\
\hline $1922-1929$ & 0.8 & NA \\
\hline $1930-1939$ & 0.5 & 0.0 \\
\hline $1940-1949$ & 2.5 & 0.2 \\
\hline $1950-1959$ & 2.1 & 0.0 \\
\hline $1960-1969$ & 3.1 & 0.3 \\
\hline $1970-1979$ & 4.9 & 0.3 \\
\hline $1980-1989$ & 9.3 & 0.8 \\
\hline $1990-1999$ & 18.8 & 1.3 \\
\hline $2000-2009$ & 21.4 & 1.7 \\
\hline $2010-2019$ & 42.4 & 6.5 \\
\hline
\end{tabular}

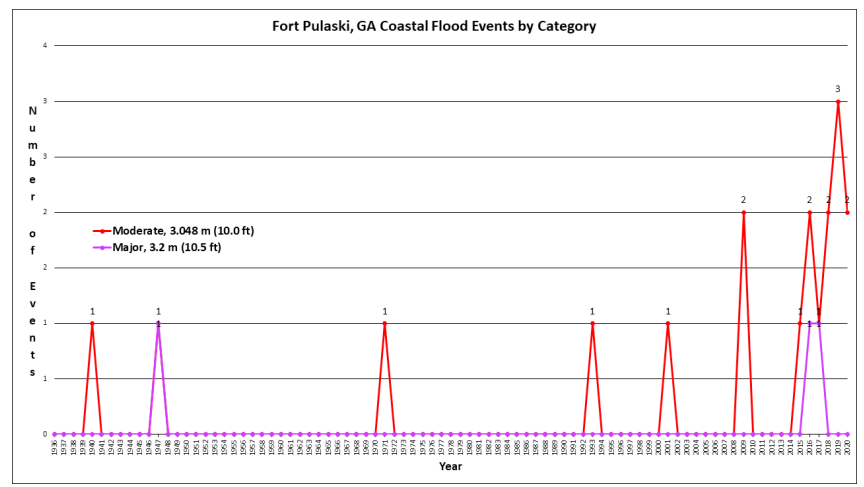

Figure 7. Same as in Figure 4, but for Fort Pulaski, GA (1936-2020).

developed following the methods and procedures first published in Coz et al. (2021). In summary, Coz et al. (2021) explored the correlation between the high tide tidal departure (Delta High) and the previous low tide tidal departure (Delta Low) for coastal flood events at Charleston Harbor from 1996 to 2014. For reference, tidal departure is calculated as the difference between the observed tide value and the astronomical expected value and can be positive or negative. Coastal flood events were recorded and then assigned a synoptic category based on the surface pressure anomaly patterns leading up to and during the events. The synoptic categories used were:

- Category A: Anticyclonic

- Category B: Cyclonic

- Category C: Frontal

- Category D: Neutral

- Category E: Tropical

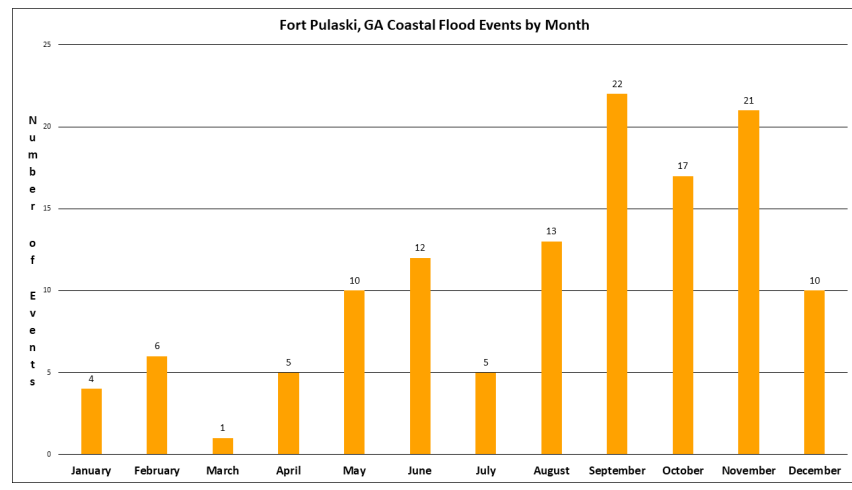

Figure 8. Same as in Figure 5, but for Fort Pulaski, GA (1936-2020).

After coastal flood events were individually analyzed and assigned to one of these categories, regression analysis was performed, and $\mathrm{R}^{2}$ calculated, using the Delta Low (independent variable) and the Delta High (dependent variable). For reference, $\mathrm{R}^{2}$ is the coefficient of determination and can quantify the strength of a relationship between two variables (Wilks 2011). The resulting regression equation for each category could then be used to produce a short-term forecast in a realtime event once the category was determined and the low tide tidal departure was known. Tropical events (Category E) were removed from consideration in the analysis due to the complex nature and impact of storm surge on tide heights under the influence of a tropical cyclone. Also, tropical events can produce extremely large positive tidal departure values that will result in a relatively small number of events having a significant impact on the statistical relationship derived from Delta Low and Delta High. Finally, when coastal flood events 
occurred on consecutive days, the entire sequence of days was considered one event rather than each individual tide.

For the purposes of this study, the methods and procedures of Coz et al. (2021) were followed except that each coastal flood event was treated as an individual event, regardless of whether or not it occurred on consecutive days as part of a multi-day event. The project had four primary objectives:

1. Extend the Charleston Harbor database up to 2018

2. Expand the project to Fort Pulaski using the same methods and procedures

3. Use coastal flood events from 2019 and 2020 as a test case to evaluate the accuracy of the forecast tool

4. Implement the tool operationally

Extending the Charleston Harbor database to 2018 was important because, as noted in section 2, the number of coastal flood events has increased significantly in recent years. At Charleston Harbor, 427 coastal flood events occurred during the 1996 to 2014 time period (average of 22.5 events per year) while 201 events occurred from 2015 through 2018 (average of 50.3 events per year). Extending the database to 2018 increases the events considered for forecast tool regression analysis by 47\%. Also, 2019 through 2020 provided an excellent opportunity to evaluate the accuracy of the forecast tool as this two-year period represents the most active on record at both Charleston Harbor and Fort Pulaski. All regression analysis was performed using Microsoft Excel to create a scatterplot of Delta Low (x axis) and Delta High (y axis).

To conduct the project through the same methods and procedures at Fort Pulaski, a couple of special considerations were required. First, when the project began, the coastal flood threshold at Fort Pulaski was $2.804 \mathrm{~m}(9.2 \mathrm{ft})$ MLLW. NWS Charleston increased the Minor flood threshold from $2.804 \mathrm{~m}(9.2 \mathrm{ft})$ MLLW to $2.896 \mathrm{~m}$ (9.5 ft) MLLW on 1 May 2020, which was well after the project started. The Minor flood threshold was increased following coordination with local emergency management officials to address infrastructure improvements and more accurately represent the typical onset of coastal flood impacts along the southeastern Georgia coast. Therefore, the database for the tide forecast tool includes all observed peak tides that reached or exceeded $2.804 \mathrm{~m}(9.2 \mathrm{ft})$
MLLW during the 1996 to 2018 time period. Second, the Fort Pulaski tide site is susceptible to the significant drawdown and surges of water produced by ships passing through a narrow channel, known also as Bernoulli wakes (Rapaglia et al. 2011). These wakes can produce tide level fluctuations on the order of several tenths of a foot from one six-minute observation to the next, causing the high and low tide values to be artificially too high or too low (Dixon 2019). Because the study relies on the tidal departure at both low and high tide, Bernoulli wakes can impact the calculation of Delta Low and Delta High, as well as the resulting relationship between the two. Fort Pulaski is especially susceptible to Bernoulli wakes because of its proximity to the narrow shipping channel used by large cargo ships entering and departing the Port of Savannah. Bernoulli wakes were noted at both low and high tide, though they were more common at high tide as large ships tend to navigate the river when the water level is elevated. To mitigate the impact of Bernoulli wakes, the NOS CO-OPS $\mathrm{H} / \mathrm{L}$ water level dataset was utilized to replace the six-minute data when the wakes were observed. For reference, Bernoulli wakes were observed in $\sim 35 \%$ (77 out of 222) of the non-tropical coastal flood events used in the Fort Pulaski regression analysis to calculate Delta High, and $22 \%$ (48 out of 222) of the low tides used to calculate Delta Low (section 3c).

\section{b. Charleston Harbor, South Carolina results}

For the 1996 to 2018 time period, 628 coastal flood events were identified at Charleston Harbor. All events were then assigned synoptic categories as described in section 3a, which were then distributed as follows: 242 events in Category A ( 39\%), 141 events in Category B ( $22 \%), 132$ events in Category C ( 21\%), 64 events in Category D $(\sim 10 \%)$, and 49 events in Category E $(\sim 8 \%)$. After the Category E (Tropical) events were removed, 579 total events were included in the regression analysis. When all 579 non-tropical events are considered in a plot of Delta Low versus Delta High (all-inclusive), there is a strong correlation with a $\mathrm{R}^{2}$ value of 0.7384 (Fig. 9). For the individual categories, the $\mathrm{R}^{2}$ varies from a high of 0.7661 in Category $\mathrm{C}$ to a low of 0.5586 in Category D (Fig. 10). A quadratic fit was used for the regression analysis because it resulted in a slightly higher $\mathrm{R}^{2}$ value than a linear fit for the allinclusive analysis and for each of the category analyses (not shown).

To test the accuracy of the regression equations 


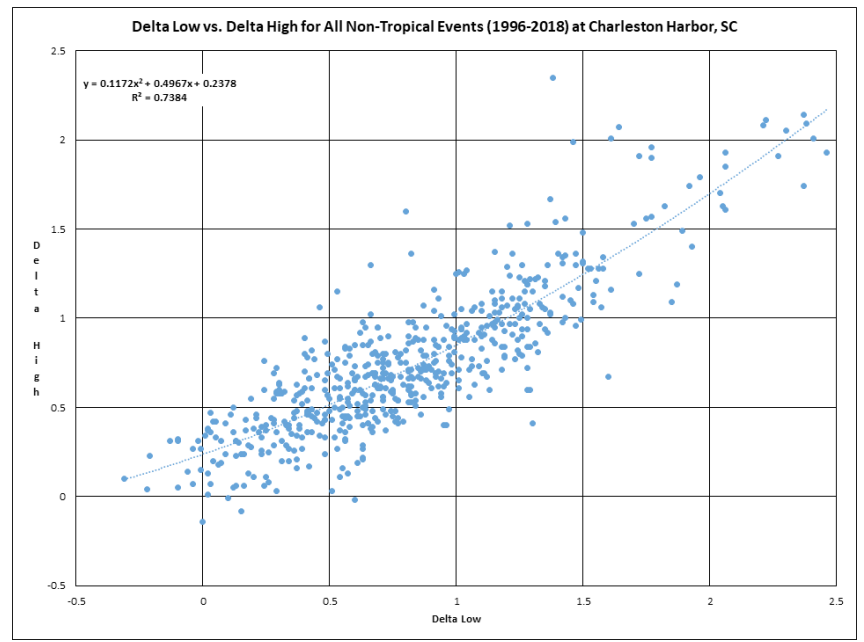

Figure 9. Scatterplot of Delta Low versus Delta High for all non-tropical coastal flood events at Charleston Harbor, SC (1996-2018).

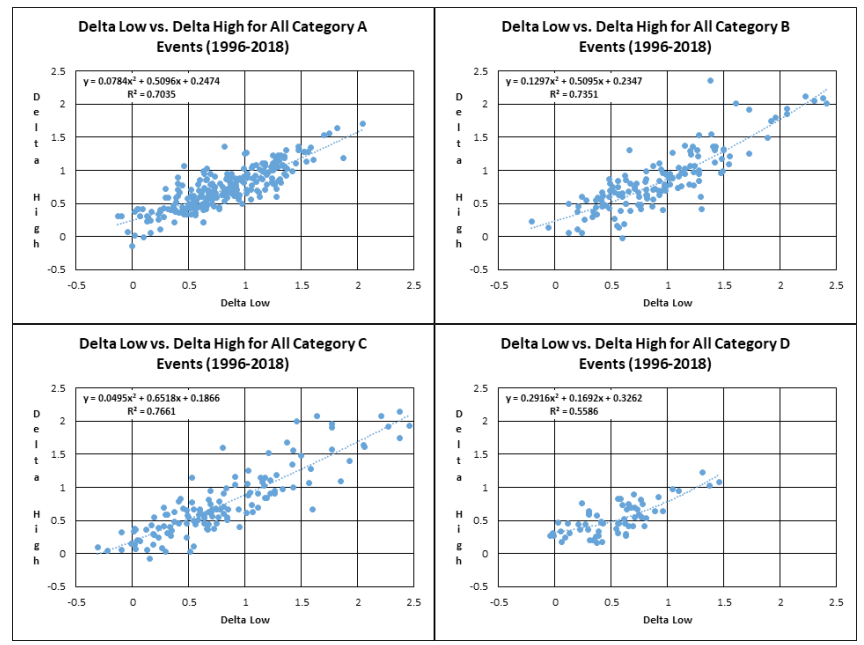

Figure 10. Scatterplots of Delta Low versus Delta High for Category A, B, C, and D coastal flood events at Charleston Harbor, SC (1996-2018).

derived from the all-inclusive dataset and the individual categories, coastal flood events from 2019 and 2020 were evaluated. There were 157 total coastal flood events in 2019 and 2020, with ten of those being identified as Category E (tropical) events. The remaining 147 non-tropical events were then assigned categories with 68 Category A events, 25 Category $\mathrm{B}$ events, 32 Category $\mathrm{C}$ events, and 22 Category D events. Forecasts were generated for these events utilizing the appropriate category-based regression equation, and the all-inclusive regression equation that was based on all of the non-tropical events in the 19962018 period regardless of synoptic category. Based on
Mean Absolute Error (MAE), there was no meaningful difference noted across any of the categories when comparing the category-specific equations to the allinclusive equations (Table 2). When averaged across all events, the all-inclusive equation and the categoryspecific equations both produced an MAE of $0.049 \mathrm{~m}$ $(0.16 \mathrm{ft})$. Similar performance is also noted when the forecast MAE's for individual events are placed into range bins (Table 3 ). The category-specific equations produced a forecast that was within $0.027 \mathrm{~m}(0.09 \mathrm{ft})$ of the observed values $\sim 41 \%$ of the time (61 of 147 events) while the all-inclusive equation was within $0.027 \mathrm{~m}(0.09 \mathrm{ft}) \sim 39 \%$ of the time (57 of 147 events). Furthermore, both forecast equations had a MAE that was within $0.061 \mathrm{~m}(0.20 \mathrm{ft})$ of the observed tide level $\sim 68 \%$ of the time.

\section{c. Fort Pulaski, Georgia results}

For the 1996 to 2018 time period, 236 tides of $2.804 \mathrm{~m}(9.2 \mathrm{ft})$ MLLW or higher were identified at Fort Pulaski. All events were then assigned synoptic categories that broke down as 106 events in Category A $(\sim 45 \%), 48$ events in Category B ( $20 \%), 49$ events in Category C ( $\sim 21 \%), 19$ events in Category D $(\sim 8 \%)$, and 14 events in Category E ( $\sim 6 \%)$. After the Category E (Tropical) events were removed, 222 total events were included in the regression analysis. When all 222 non-tropical events are considered in a plot of Delta Low versus Delta High (all-inclusive), the $\mathrm{R}^{2}$ value was 0.4938 (Fig. 11). For the individual categories, the $\mathrm{R}^{2}$ varies from a high of 0.5582 in Category $\mathrm{C}$ to a low of 0.4343 in Category B (Fig. 12). Similar to the Charleston Harbor results, a quadratic fit was used for the regression analysis because it resulted in a slightly higher $\mathrm{R}^{2}$ value than a linear fit for the all-inclusive analysis and for each of the category analyses (not shown).

It is quite apparent that the correlation between Delta Low and Delta High is notably less for Fort Pulaski $\left(\mathrm{R}^{2}=0.4938\right)$ than it is for Charleston Harbor $\left(\mathrm{R}^{2}=0.7384\right)$. This lesser correlation is not explicitly examined in this study but there are some possible reasons for it. First, though the influence of Bernoulli wakes was mitigated by using the NOS H/L data, they could still have an impact on the relationship of water levels at high and low tide. Also, the geographic location of the tide gauges could have an important effect (Fig. 13). The Fort Pulaski tide gauge is located at the mouth of the Savannah River, which is a large 
Table 2. MAE in m (ft) for coastal flood events (2019-2020) in each synoptic category using the category-specific regression equations and the all-inclusive regression equation for Charleston Harbor, SC.

\begin{tabular}{|c|c|c|}
\hline Synoptic Category & $\begin{array}{c}\text { MAE for Category-Specific } \\
\text { Equation }\end{array}$ & $\begin{array}{c}\text { MAE for All-Inclusive } \\
\text { Equation }\end{array}$ \\
\hline A & $0.049(0.16)$ & $0.049(0.16)$ \\
\hline B & $0.061(0.20)$ & $0.061(0.20)$ \\
\hline C & $0.049(0.16)$ & $0.049(0.16)$ \\
\hline D & $0.040(0.13)$ & $0.034(0.11)$ \\
\hline Average & $0.049(0.16)$ & $0.049(0.16)$ \\
\hline
\end{tabular}

Table 3. MAE range bins in $\mathrm{m}(\mathrm{ft})$ for coastal flood events (2019-2020) using the category-specific regression equations and the all-inclusive regression equation for Charleston Harbor, SC.

\begin{tabular}{|c|c|c|}
\hline MAE Range & $\begin{array}{c}\text { Category-Specific Equations } \\
\text { (number of events) }\end{array}$ & $\begin{array}{c}\text { All-Inclusive Equation } \\
\text { (number of events) }\end{array}$ \\
\hline $0.027(0.09)$ or less & 61 & 57 \\
\hline $0.030(0.10)-0.058(0.19)$ & 40 & 43 \\
\hline $0.061(0.20)-0.088(0.29)$ & 21 & 24 \\
\hline $0.091(0.30)-0.119(0.39)$ & 14 & 12 \\
\hline $0.122(0.40)-0.149(0.49)$ & 6 & 6 \\
\hline $0.152(0.50)$ or more & 5 & 5 \\
\hline
\end{tabular}

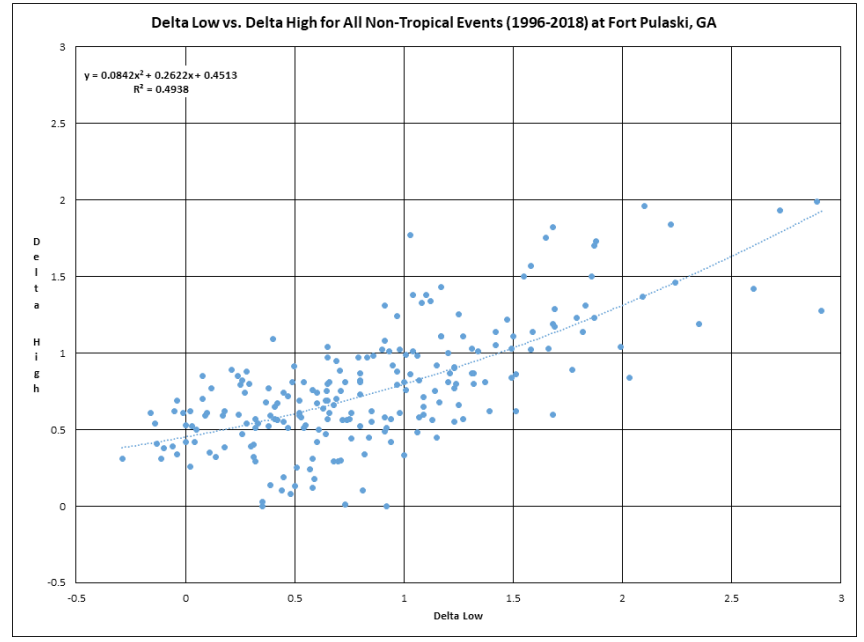

Figure 11. Same as in Figure 9, but for Fort Pulaski, GA (1996-2018).

river that runs along the entire border between Georgia and South Carolina. Meanwhile, the Charleston tide gauge is situated within a defined harbor that is connected to smaller rivers including the Ashley River, the Cooper River, and the Wando River. The differences in freshwater influences at these two locations could influence tidal departures at both high and low tide, as well as the resulting correlation. A detailed study

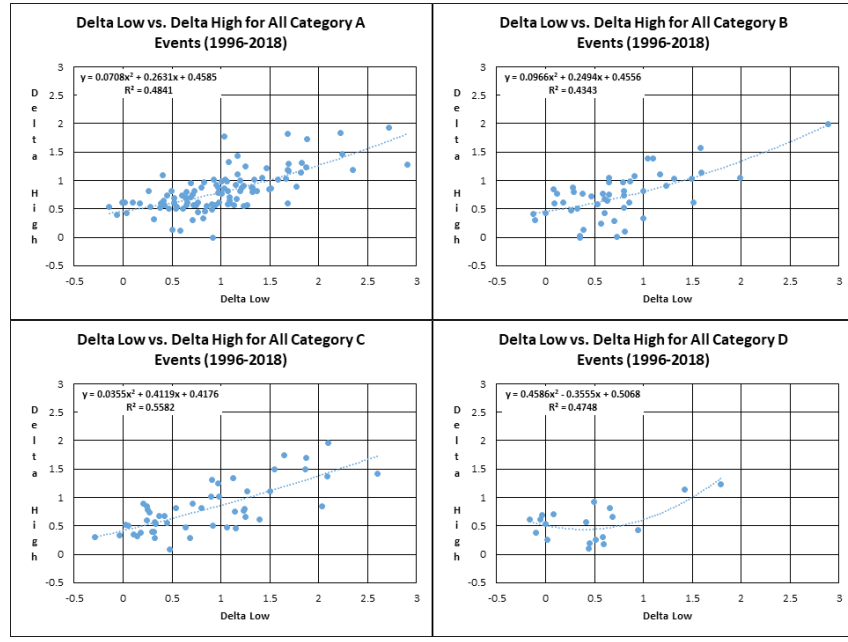

Figure 12. Same as in Figure 10, but for Fort Pulaski, GA (1996-2018).

investigating reasons for the disparity in $\mathrm{R}^{2}$ for Fort Pulaski and Charleston Harbor is worthy of future work.

As was done for Charleston Harbor, to test the accuracy of the Fort Pulaski regression equations, coastal flood events from 2019 and 2020 were assessed. There were 80 total coastal flood events, with seven of those being identified as Category E (tropical) events. The remaining 73 non-tropical events were 


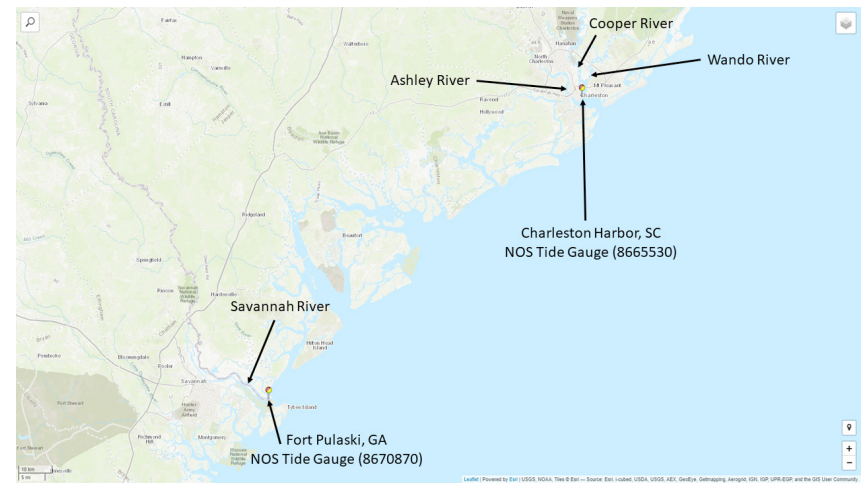

Figure 13. Map showing the locations of NOS tide gauges in Charleston Harbor, SC and Fort Pulaski, GA. Map image taken from NOS CO-OPS Tides and Currents web page (link).

then assigned categories with 40 Category A events, 17 Category B events, 8 Category $\mathrm{C}$ events, and 8 Category $\mathrm{D}$ events. These events were used to calculate a forecast based on the appropriate category-based regression equation, and the all-inclusive regression equation that considered all non-tropical events in the 1996 through 2018 period regardless of synoptic category. As expected, because of the significantly lower $\mathrm{R}^{2}$ value, the MAE was considerably higher across the board compared to Charleston Harbor (Table 4). However, much like Charleston, there was no substantial difference noted in MAE across any of the categories when comparing the category specific equations to the all-inclusive equations. When averaged across all events, the all-inclusive equation and category specific equations both produced an MAE of $0.070 \mathrm{~m}(0.23 \mathrm{ft})$. When the forecast MAE results for individual events are placed into range bins, the similarity between the performances of the two equations remains apparent. Both the category-specific equations and the allinclusive equation produced a forecast that was within $0.030 \mathrm{~m}(0.10 \mathrm{ft})$ of the observed values $22 \%$ (16 of 73 events) of the time (Table 5). Furthermore, the MAE was within $0.061 \mathrm{~m}(0.20 \mathrm{ft})$ of the observed tide level $\sim 45 \%$ of the time for the category specific equations and $49 \%$ of the time for the all-inclusive equation.

\section{Conclusions}

Coastal flooding has been identified in the scientific literature as a significant and increasing threat to life and property in coastal regions of the country, including southeastern Georgia and southeastern South Carolina. As sea level continues to rise, coastal flooding is occurring more frequently at all levels of impact (Minor, Moderate, and Major). Not only is the occurrence of flooding increasing across decadal time scales, but the increasing frequency of flooding is particularly noticeable over the last five years, as seen in data collected from tide gauges at Charleston Harbor, South Carolina and Fort Pulaski, Georgia. In order to aid in the decision making process for issuing Coastal Flood Watches, Warnings, and Advisories at NWS Charleston, a tide forecast tool has been adapted from Coz et al. (2021). Initial results using 2019 and 2020 coastal flood events show that the forecast tool has utility in predicting peak tide heights for non-tropical coastal flood events. Though the accuracy is noticeably higher at Charleston Harbor than it is at Fort Pulaski, it is believed that the tool can be beneficial for use at both sites.

The final objective of the project is the implementation of the forecast tool into the operational environment at NWS Charleston. To make the forecast tool useful operationally, it needed to be simple to use, fast, and easy to access. First, it was determined that using the all-inclusive regression equations would be best because there was virtually no difference in the forecast performance of the category-specific equations and the all-inclusive equations at both Charleston Harbor and Fort Pulaski. Using the allinclusive equations simplifies the process and removes any ambiguity in determining the synoptic category of an event in real time. The forecast tool requires very little operational time as the only input is the low tide tidal departure, and the output can be easily calculated using a locally created web interface. However, just like any other form of forecast guidance, the tool exhibits some limitations. The tool is not meant to be used during tropical events as they were removed from consideration during the project. This means the tool will not be utilized during the events where the most extreme water levels are likely to occur. Also, because the low tide tidal departure is needed to calculate the forecasted high tide tidal departure, the forecast tool has a lead time of no more than approximately six hours, a typical interval between low tide and the subsequent high tide. With this time limitation in mind, the forecast tool is best utilized to refine TWL forecasts and finalize Coastal Flood Watch, Warning, and Advisory decisions. There are several possible avenues for future work extending from this study. First, the applicability of the forecast tool and associated development process could be assessed at other tide gauge locations in the NWS 
Table 4. MAE in m (ft) for coastal flood events (2019-2020) in each synoptic category using the category-specific regression equations and the all-inclusive regression equation for Fort Pulaski, GA.

\begin{tabular}{|c|c|c|}
\hline Synoptic Category & $\begin{array}{c}\text { MAE for Category-Specific } \\
\text { Equation }\end{array}$ & $\begin{array}{c}\text { MAE for All-Inclusive } \\
\text { Equation }\end{array}$ \\
\hline A & $0.073(0.24)$ & $0.076(0.25)$ \\
\hline B & $0.058(0.19)$ & $0.058(0.19)$ \\
\hline C & $0.067(0.22)$ & $0.070(0.23)$ \\
\hline D & $0.088(0.29)$ & $0.061(0.20)$ \\
\hline Average & $0.070(0.23)$ & $0.070(0.23)$ \\
\hline
\end{tabular}

Table 5. MAE range bins in $\mathrm{m}(\mathrm{ft})$ for coastal flood events (2019-2020) using the category-specific regression equations and the all-inclusive regression equation for Fort Pulaski, GA.

\begin{tabular}{|c|c|c|}
\hline MAE Range & $\begin{array}{c}\text { Category-Specific Equations } \\
\text { (number of events) }\end{array}$ & $\begin{array}{c}\text { All-Inclusive Equation } \\
\text { (number of events) }\end{array}$ \\
\hline $0.027(0.09)$ or less & 16 & 16 \\
\hline $0.030(0.10)-0.058(0.19)$ & 17 & 20 \\
\hline $0.061(0.20)-0.088(0.29)$ & 18 & 14 \\
\hline $0.091(0.30)-0.119(0.39)$ & 12 & 13 \\
\hline $0.122(0.40)-0.149(0.49)$ & 7 & 6 \\
\hline $0.152(0.50)$ or more & 3 & 4 \\
\hline
\end{tabular}

Charleston area and in other NWS forecast areas. In order to utilize the forecast tool in other coastal regions and other tide gauge locations, at a minimum, a set of coastal flood events must be collected, Delta High and Delta Low must be calculated for each event, and then regression analysis must be performed based on the Delta High and Delta Low values. Though a complete synoptic classification of all events is not necessarily required, tropical events must be identified so they can be removed from consideration in the regression analysis. Finally, the contributions of meteorological influences (including wind speed and direction and air pressure) to the observed tidal departure could be investigated and quantified. Knowing the precise magnitude of tidal departure produced by certain wind speed and wind direction combinations, as well as air pressure values, could help produce an improved tide forecast and increase confidence in the issuance of Watch, Warning, and Advisory products.

Acknowledgments. This effort is the result of a collaborative project between NWS Charleston and the College of Charleston funded under Subaward \#Z1623457 with the University Corporation for Atmospheric Research (UCAR) under Cooperative Agreement No. NA11NWS4670004 with the National Oceanic and
Atmospheric Administration (NOAA), United States Department of Commerce (DoC). Thank you to Grant Farmer and Jon Leighton Gardner for their vital work on this project as part of the student volunteer program at NWS Charleston. Also, thank you to Steve Rowley and Jeff Waldstreicher for reviewing and improving this manuscript prior to submission.

\section{REFERENCES}

Campbell Jones, S., T. Ruppert, E. Deady, H. Payne, J. S. Pippin, L.-Y. Huang, and J. Evans, 2019: Roads to nowhere in four states: State and local governments in the Atlantic Southeast facing sea-level rise. Columbia Journal of Environmental Law, 44 (1), 67-136, Crossref.

Charleston 2019: Flooding and Sea Level Rise Strategy, 2nd Edition. City of Charleston, SC. [Available online at https://www.charleston-sc.gov/DocumentCenter/ View/20299], February 2019.

Coz, J., F. Alsheimer, and B. L. Lindner, 2021: A climatologybased forecast tool for coastal flooding in the low country. J. Appl. Meteor. Climatol., 60 (7), 893-908, Crossref. 
Dixon, N., 2019: The effects of ship-induced Bernoulli wakes on the Savannah River, Georgia. 44th Annual Meeting, Huntsville, AL, National Weather Association. [Available online at https://nwas.org/annual-meetingevents/annual-meeting/meeting-agenda/].

Moftakhari, H. R., A. AghaKouchak, B. F. Sanders, D. L. Feldman, W. Sweet, R. A. Matthew, and A. Luke, 2015: Increased nuisance flooding along the coasts of the United States due to sea level rise: Past and future. Geophysical Research Letters, 42, 9846-9852, Crossref.

_ A. AghaKouchak, B. F. Sanders, and R. A. Matthew, 2017: Cumulative hazard: The case of nuisance flooding. Earth's Future, 5, 214-223, Crossref.

Morris, J. T. and K. A. Renken, 2020: Past, present, and future nuisance flooding on the Charleston peinisula. PLoS ONE, 15 (9), e0238770, Crossref.

NOAA 2019. What is a perigean spring tide? National Ocean Service [Available at https://oceanservice.noaa.gov/ facts/perigean-spring-tide.html].

Rapaglia, J., L. Zaggia, K. Ricklefs, M. Gelinas, and H. Bokuniewicz, 2011: Characteristics of ships' depression waves and associated sediment resuspension in Venice Lagoon, Italy. Journal of Marine Systems, 85, 45-56, Crossref.

Sweet, W., J. Park, J. Marra, C. Zervas, and S. Gill, 2014: Sea Level Rise and Nuisance Flood Frequency Changes around the United States. NOAA Technical Report NOS CO-OPS 073, 58 pp, Crossref.

, R. E. Kopp, C. P. Weaver, J. Obeysekera, R. M. Horton, E. R. Thieler, and C. Zervas, 2017: Global and Regional Sea Level Rise Scenarios for the United States. NOAA Technical Report NOS CO-OPS 083, 56 pp, Crossref.

, G. Dusek, J. Obeysekera, and J. J. Marra, 2018: Patterns and Projections of High Tide Flooding Along the U.S. Coastline Using a Common Impact Threshold. NOAA Technical Report NOS CO-OPS 086, 56 pp, Crossref.

Thurman, H. V. and A. P. Trujillo, 2004: Introductory Oceanography, 10th ed., Prentice Hall, 608 pp.

Wilks, D. S., 2011: Statistical Methods in the Atmospheric Sciences (Third Edition). Academic Press, 676 pp. 